\section{Fossilized eggs from Illinois}

SIR - Apart from the egg capsules of chondrichthyans ${ }^{1}$, fossilized eggs from the Palaeozoic are exceedingly rare. I report here the discovery of fossilized eggs in a siderite concretion from the Middle Pennsylvanian, Francis Creek Shale (Carbondale Formation, Desmoinesian Series, Westphalian C-D, about 300 million years old) in the Mazon Creek area of northeastern Illinois. Differential staining of the siderite matrix indicates that the circular ova were held together in a gelatinous string.

The area around Mazon Creek is one of the most important sources of late Palaeozoic fossils. The fossiliferous concretions are famous by virtue of the superb preservation of soft-bodied organisms, many of which are either unique to this area or represent the earliest or only known record of an important taxonomic group ${ }^{2}$. The taxonomically diverse assemblage consists of more than 500 plant and animal species derived from two main faunal associations: the Braidwood biota, of brackish freshwater and coal swamp habitats; and the Essex biota, of nearshore marine habitats ${ }^{3}$. The fossilized egg strand (Royal Ontario Museum 47490) was collected by Karlene and Steve Ramsdell from a pit 11 spoil heap

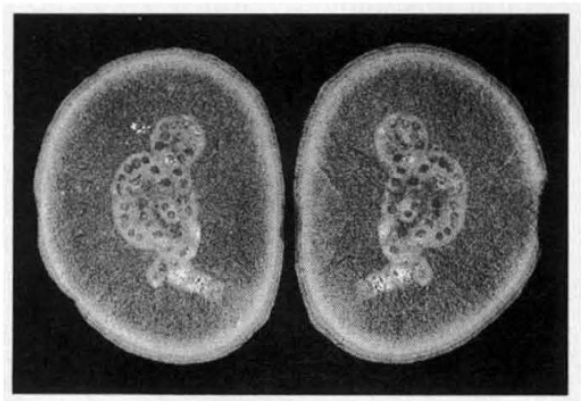

Fossilized eggs from the Middle Pennsylvanian, Francis Creek Shale near Braidwood, Illinois (ROM 47490). Part and counterpart. Nodule maximum length is $58 \mathrm{~mm}$.

of the now abandoned shallow shaft mines of the Peabody Coal Company. Most of the organisms from pit 11 are of the Essex (marine) biota, but in this area, a 2-5-km-wide zone of mixing between the Braidwood and Essex assemblages has been well documented ${ }^{4}$. Unfortunately, as a result of this faunal mixing, it is not possible to ascertain whether the eggs were derived from a marine or a freshwater organism.

The spawn, preserved in part and counterpart (see figure), split through the bedding plane on which it came to rest. Dark circular spots represent the remnants of about 40 eggs held in at least one but perhaps two strands. The diameter of the ova range from about $1.5-1.7 \mathrm{~mm}$. The effects of preservation on the diameter of the ova are unknown. A gelatinous string, now seen as a lightcoloured staining of the siderite, held the eggs in a single row. The preserved diameter of the once jelly-like sheath ranges from about 3 to $3.8 \mathrm{~mm}$. Two other specimens are known (ROM 48443 and ROM 48444), but their gelatinous sheaths are not as clearly preserved as in ROM 47490.

Among extant organisms, several groups spawn egg strands. Some opisthobranch molluscs extrude eggs in gelatinous ribbons or sheets ${ }^{5}$. However, opisthobranch eggs range in diameter from about $40-400 \mu \mathrm{m}$, with most approximately $100 \mu \mathrm{m}$ in diameter. Among vertebrates, at least five species within the Teleostei extrude egg strings or ribbons ${ }^{6}$. The largest number of species spawning egg strings that resemble those from Mazon Creek are to be found within the Amphibia?. Unfortunately, there are no known diagnostic features by which these fossilized eggs can be assigned taxonomically.

STEPHEN J. Godfrey

Royal Tyrrell Museum of Palaeontology, Box 7500, Drumheller.

Alberta TOJ OYO, Canada

1. Zidek, J. J. Paleont. 50, 907-915 (1976).

2. Baird, G. C. in Mazon Creek Fossils (ed. Nitecki, M. H.) 41-67 (Academic, New York, 1979).

. Schram, F. R. in Mazon Creek Fossils (ed. Nitecki, M. H.) 159-190 (Academic, New York, 1979).

4. Baird, G. C., Shabica, C. W., Anderson, J. L., Richardson, E. S. Jr J. Paleont. 59, 253-281 (1985).

. Thompson, T. E. Biology of Opisthobranch Molluscs (The Ray Society, London, 1976)

6. Breder, C. M. Jr \& Rosen, D. E. Modes of Reproduction in Fish (Natural History Press, New York, 1966).

Duellman. W. E. \& Trueb, L. Biology of Amphibians (McGraw-Hill, New York, 1986)

\section{No improvement in running?}

SIR - B. J. Whipp and S. A. Ward (Nature 355, 25; 1992) find that if they linearly extrapolate men's and women's running speeds, they obtain the result that women will overtake men in the marathon by the year 2000 and will overtake men in the 200 -metre dash by the year 2050 . The authors are apparently willing to extrapolate speeds in the 200-metre dash to about the year 2050 . Using their graphs as published in Nature, by the year 2050 , women will be able to run the marathon at a greater average speed than either men or women will be able to run 800 metres! This is certainly an astonishing result, and well illustrates the pitfalls of extrapolation.

My own view is that the reason the rate of improvement is greater for women than for men is that women's running is a younger sport. As the num- ber of women runners increases from a small sample of the population to a more representative sample, it is natural that speed will improve. This improvement will come on top of the greater speeds arising from increasing body size and better training methods, which presumably are common to men and women, although not necessarily to the same degree. Marathon speeds have improved the most because it was only relatively recently that the marathon was considered to be a proper distance for women.

Department of Physics,

DON B. LICHTENBERG

Indiana University,

Bloomington, Indiana 47405, USA

SIR - The picture painted by B. J. Whipp and S. A. Ward (Nature 355, 25; 1992), that women's running events are improving by leaps and bounds, is in sharp contrast with reality. Consider, for example, the prediction of a lowering of about 20 minutes for the marathon record within 6 years: the truth is that in the past 7 years the record has not improved by so much as a second.

Women's athletics has been declining recently: in the 1,500 metres, for example, the performances at 50th and 100th place in the 1984 world lists would, 5 years later, have given rankings as 16th and 46th, respectively. The current world record has stood since 1980 . In the past 3 years, nobody has come within 6 seconds of it. Thus, contrary to Whipp and Ward's claim, the gap between women's and men's performance is widening (men's performance is fairly stable).

A. LENNART JULIN

Swedish Athletic Association,

Gästrikegatan 14,

S-113 62 Stockholm, Sweden

SIR - If the predictions of B. J. Whipp and S. A. Ward (Nature 355, 25; 1992) are to be believed, athletics administrators will soon be faced with a different set of problems over sex testing than those currently taxing them. In the Olympic Games due to take place in the year 2000 , it may be potentially advantageous in terms of medal-winning for a woman marathon runner to masquerade as a man and race in the men's event. This advantage will progressively apply through the shorter events during the twenty-first century. In my view, the only equitable solution (which completely obviates the need for sex testing) is for the distinction between the sexes to be abandoned after 2050 in running events of 200 metres and beyond.

P. H. SUGDEN

Department of Cardiac Medicine, National Heart and Lung Institute,

Dovehouse St,

London SW3 6LY, UK 